Running head: ACCESS TO SERVICES FOR OLDER PEOPLE

\title{
Age friendly cities and communities: Access to Services for Older People
}

Tamara Lowen ${ }^{1}$, Melanie T. Davern ${ }^{2}$, Suzanne Mavoa $^{2}$, Kathleen Brasher ${ }^{3}$

${ }^{1}$ Melbourne School of Design, Architecture, Building and Planning, University of Melbourne, Parkville, Victoria, 3010. Telephone: (03) 83443184 Email: tamara.lowen@unimelb.edu.au

${ }^{2}$ McCaughey VicHealth Unit of Community Wellbeing, School of Population and Global Health, University of Melbourne: Level 5, 207 Bouverie St, Carlton Victoria,

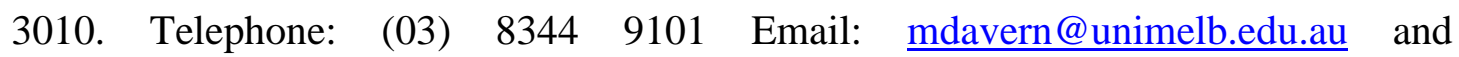
suzanne.mavoa@unimelb.edu.au

${ }^{3}$ Council of the Ageing, Victoria: Level 4, Block Arcade, 98 Elizabeth St, Melbourne, Victoria, 3000. Telephone: (03) 96544443 Email: KBrasher@cotavic.org.au

Address all correspondence to Dr Melanie Davern, McCaughey VicHealth Unit of Community Wellbeing, School of Population and Global Health, University of Melbourne: Level 5, 207 Bouverie St, Carlton Victoria, 3010.

Telephone: +61 383443184 Fax: +61 393482832 Email:

mdavern@unimelb.edu.au 


\begin{abstract}
Australia's population is ageing rapidly, and our cities and communities need to be prepared to accommodate the needs of this increasing demographic to facilitate ageing in place. Ageing in place - where older people remain active and engaged members of the community - is influenced by access to services in the community. This paper introduces an indicator of access to services for older people that can be used to plan for age friendly cities. Development of the indicator was informed by qualitative research with older people and key stakeholders. Geographic Information Systems (GIS) were used to create the indicator and map locations of key services in relation to population based ageing demographics in Victoria, Australia. Areas of comparative advantage and disadvantage were identified, with results demonstrating that most regional municipalities had fewer services to access than their metropolitan counterparts. This research provides the first attempt to measure and compare service provision for older people across the state of Victoria.
\end{abstract}

Keywords: older people; access to services; planning; age friendly; geographic information systems (GIS).

Word count: 5900 


\section{Introduction}

Adequately planning for population change is one of the biggest challenges for modern urban planning. In Australia, the resident population is expected to increase from 22.7 million in 2012 to between 42 and 70 million people in 2101 (Australian Bureau of Statistics, 2013). This population growth is also associated with a steadily increasing ageing population with the current proportion of people aged 65 years and over in Australia predicted to near double to $25 \%$ by 2101 , and the proportion of people aged over 85 years expected to triple (Australian Bureau of Statistics, 2013). In Victoria, the number of people aged over 65 years is expected to triple by 2051 with most population growth expected across the newer and sprawling outer growth area suburbs of Melbourne (Department of Transport Planning and Local Infrastructure, 2014). This growth is influenced by the ageing baby boomer generation, and also by declining birth rates and rising average life expectancy (Department of Planning and Community Development, 2012). The rapid growth in this demographic will have economic, social and health consequences for our cities and communities, particularly given older people's changing preferences and expectations about housing and facilities as well as current trends favouring ageing in place, rather than traditional aged care facilities (Brown, 2011; Engels \& Liu, 2011).

Successful ageing in place depends on older people having access to relevant service needs in the community. These include access to medical care, retail, recreation, affordable entertainment, social facilities, public transport, housing, home services, and environmental 'facilities' such as public open space. However, the essential services that enable ageing in place and their current spatial distribution and provision are not well understood. Previous studies regarding ageing in place have explored the importance of transport accessibility (Engels \& Liu, 2011, 2012; Wiles, Leibling, Guberman, Reeve, \& Allen, 2011), availability of health care (Giles, Halbert, Gray, Cameron, \& Crotty, 2009; Wiles et al., 2011), services (Wiles et al., 2011), support with housework, meal preparation and shopping (Wilkinson-Meyers, Brown, McLean, \& Kerse, 2014), housing and homelessness (Lipmann, 2009), social participation and civic engagement in rural areas (Davis, Crothers, Grant, Young, \& Smith, 2012; Wiles et al., 2011), disadvantage in rural areas (Winterton \& Jeni, 2011), built form (Burton, Mitchell, \& Stride, 2011) and social networks (Gardner, 2011; 
Wiles et al., 2011). In these studies, services and amenities are usually referred to in general terms. This study extends on previous research by investigating which services are used and considered essential by older people themselves to support their wellbeing in their communities. Ageing in place is a broad concept that older people define differently to policy makers: older people refer to ageing in place in terms of connections to people, places, services, contexts and groups and not just buildings, homes or houses (Wiles et al., 2011). These subtle differences also suggest the need for more participatory research with older people that is centred on their needs and wants (Wiles et al., 2011).

\section{The Importance of Services in Age Friendly Cities}

Providing access to services encourages participation in the community and provides a reason for older people to get out, and actively engage and connect with their local area. The provision of services is consistent with the theoretical foundations of Age friendly cities and communities (World Health Organisation, 2007) which promotes accessible and inclusive environments where older people have optimal opportunities for health, participation and security to improve their quality of life as they age (Plouffe \& Kalache, 2011). Most importantly, the World Health Organisation's (WHO) definition of Age Friendly Cities recognises the importance of services to older people: "In practical terms, an age-friendly city adapts its structures and services to be accessible to and inclusive of older people with varying needs and capacities" (World Health Organisation, 2007:1). This discourse on age friendly environments has evolved in several countries including Canada, Spain, Brazil and Australia, with support from the international community, including the WHO and United Nations. The WHO identified the essential characteristics of an age friendly city and community by conducting interviews with older people across 33 cities in 19 developing countries and 14 industrialised countries (Burton et al., 2011; Plouffe \& Kalache, 2011; World Health Organisation, 2007). The project found that the neighbourhood environment and housing are paramount to facilitate active ageing that promotes the wellbeing and independence of older people (Burton et al., 2011). 
Eight topics are identified within the Age Friendly Cities framework (Figure 1) and include transportation, housing, social participation, respect and social inclusion, civic participation and employment, communication and innovation, community support and health services, and outdoor spaces and buildings (World Health Organisation, 2007). Each of these topics can be further analysed in terms of service provision, emphasising the importance of access to services in the development of Age friendly cities and communities. Previous research has established the importance of place for older people and their desire to stay living in their current accommodation and location, particularly for outright home owners and those with a mortgage (Olsberg \& Winters, 2005). Ageing in place is desirable for older people, policy makers and planners enabling older people access to existing social and service networks as well as the familiarity of their local environment (Australian Institute of Health and Welfare, 2013). However, location is an important determinant of current access to services and an environment that supports people to age well needs to be built with mutually enhancing social and physical facilities (Lui, Everingham, Warburton, Cuthill, \& Bartlett, 2009).

The development of a new spatial indicator of access to services for older provides a new measure for assessing how age friendly an existing local environment is, and supports the need for integrated evidence-based planning consistent with the Age Friendly Cities framework. This mixed methods study explores the needs and barriers to accessing services relevant to older people, culminating in the production of a new indicator of access to services specific to older people and identification of areas of comparative advantage and disadvantage in terms of service provision. In this study access is defined as geographical proximity to services and does not explore sociocultural or political factors that may influence service usage. The indicator of service availability for older people will enable planners, policy makers and community members to gain a comprehensive understanding of the spatial patterning of services and to help identify where new services are required.

\section{Methods}

Qualitative research included focus groups and interviews about the most important services needed for inclusion in the indicator and barriers that affected access to 
services for older people. Quantitative research included spatial analysis using Geographic Information Systems (GIS) to create a new indicator of access to services for older people. The method was informed by Engels and Liu's (2011) investigation of land use, travel distance and transport and the project was approved by the University of Melbourne Human Research Ethics Committee.

\section{Focus Groups and Stakeholder Interviews}

Focus group interviewing was arranged through the Council of the Ageing (COTA) which is a peak organisation representing the rights, needs and interests of older Australians. The purpose of the interviews was to gain an understanding of the needs of older people. Interviews were designed to address the following research questions: (1) what are the key services needed by older people; and (2) what are some of the barriers to accessing services for older people. Interviews were conducted with 20 community members aged 65 years and older and asked a series of questions about the services and facilities they commonly use and those they consider to be most important (Table 1). Participants were also asked to rate the importance of a range of services adapted from Engels and Liu (2011) that included shops, doctors, libraries, community centres, chemists, restaurants, banks, parks, education centres, hospitals, post offices, places of worship, newsagents, hairdressers, cinemas, pubs and gambling venues. Services were rated as 'very important', 'important' or 'not important'. Participants also identified the three services they used most frequently.

Nine semi-structured stakeholder interviews were conducted with representatives from the following organisations: the Council of the Ageing; Victorian Department of Health; Victorian Council of Social Services; Municipal Association of Victoria; and 5 local governments from the inner, middle and outer suburbs of metropolitan Melbourne and rural Victoria. The stakeholders were asked about access to services and social infrastructure for older people guided by questions on the following topics: social infrastructure and services; crucial needs and services for older people; differences across areas; needs of older people; barriers to and acceptable distances for older people to travel to access services (Table 1). 
Focus group interviews and key stakeholder interviews were conducted between July and September 2012. All interviews and focus groups were transcribed before being analysed using grounded theory to derive theories from trends and themes that emerged from the data (Babbie, 2011).

\section{Spatial Analysis}

GIS methods were used to create a new indicator of access to services for older people across all 79 Victorian Local Government Areas (LGAs), explore the location and provision of services in relation to ageing population needs across geographic locations; and identify LGAs with poor access to services.

Services identified as important in the qualitative research were sourced from existing administrative data or manually collected and geocoded before being spatially analysed and represented using GIS software (ArcGIS 10.0). Data for each selected service and current Estimated Resident Population data (Australian Bureau of Statistics, 2012) were analysed within the GIS software. Services were counted per LGA, and then service densities were calculated based on several parameters including number of services per square kilometre $\left(\mathrm{km}^{2}\right)$, number of services per 1000 people and number of services per 1000 people aged over 65 .

A measure of overall service provision by LGA was constructed by combining individual services into an aggregate measure accounting for different service densities. For example, there would be far fewer hospitals per 1000 people than General Practitioners. To account for this, the service densities were converted to a standard score or z-score and then summed to create a final aggregate measure which was converted into quintiles and mapped. Z-scores provide a mechanism to compare different types of data by giving them all a standard score based on their variance from the mean (Wimmer \& Dominick, 2010).

\section{Results}


Discussions with older people revealed that the importance of a service is not always determined by frequency of utilisation. Services most frequently used by older people were, in order of frequency, shopping, social clubs, places of worship, parks, restaurants and libraries while health services such as General Practitioners (GPs) and chemists were used less often. In comparison, services rated as most important were, in order of importance, shopping, doctors, chemists, libraries and restaurants (Figure 3). Doctors and chemists were used less often but were very important as described by the following participant:

"The doctor is vital to everyone and yet you might see them once in a blue moon, whereas socialisation is vital too and is needed on a 4 times a week basis" (Participant, 65+)

This quote also emphasises the dual role that access to services have as a means for social connection. Shopping was unanimously the most important and most frequently used service of all and provided a source of social activity and exercise in a safe and comfortable environment. An example of the importance of shopping is well described by this participant:

"The Mall Walkers - they are at Knox. That started with a lot of people who had heart attacks, they were too frightened to walk - that's why it was started because one cardiologist asked 'where would you be safe to walk'?" (Participant, 65+)

Shopping areas provide a safe, familiar environment with good public toilets, transport and amenities. Other issues raised included frustration experienced by older people from non-English speaking backgrounds, the importance of social clubs and specifically those that cater for cultural groups (i.e. Italian clubs), and that older people have the same needs as the rest of the community with respect to good service delivery. 
Stakeholder interviews raised several key themes about access to services. One issue identified was the broad definition of the term 'services' with stakeholders sharing varied positions on practical or physical understanding of services compared to services as a means for social connections and relationships within the community. The majority of responses also emphasised a holistic approach to service provision because no single service could be prioritised. Services mentioned included opportunities for shopping, health care, employment, social interaction, infrastructure, transport, education, spirituality and recreation.

\section{"I think they all form an important part of a local hub" (Local Government)}

Stakeholders recognised diversity in a population of older people and that generalising the group was problematic. This view is consistent with the WHO Age friendly cities and communities principles (Plouffe \& Kalache, 2011) and most likely a reflection of Age friendly cities and communities principles which guided policy development in 8 out of 9 stakeholders. Services mentioned most frequently by stakeholders were basic services needed for everyday life including supermarkets, health services and GPs, community centres, community groups and opportunities for learning (particularly Universities of the $3^{\text {rd }}$ Age). Transport and urban design were also raised as important influences of access to services:

"For people to be able to access things ... you need good infrastructure in terms of paths, lighting, good public transport and good options for people in terms of mobility to assist them" (Department of Health)

Other key themes identified by stakeholders included the following: discrimination and ageism; gentrification and changing demographics within suburbs; cultural backgrounds and the specific needs of refugees, migrants and Aboriginals and Torres Strait Islanders; mental illness and physical disabilities; and affordability as a barrier of housing, transport, social activities, health care and shopping. 


\section{$\underline{\text { Indicator Creation and Spatial Representation }}$}

Based on results from focus groups and stakeholder interviews eight services identified as very important to older people and key stakeholders were included in the development of the indicator. These were: hospitals; GPs; Aged Care Facilities; public transport stops; supermarkets; community centres; libraries; and Universities of the $3^{\text {rd }}$ Age. Supermarkets were included in the indicator as a representation of the shopping experience, which was highlighted as the most important and most utilised service in focus groups. Aged care was included even though it wasn't highlighted in focus groups but was included to assist policy makers with future service provision planning. . Hospitals were similarly selected for this reason, and were further emphasised in some stakeholder interviews as important services for older people. GPs were included in the indicator to address health, which was raised in focus groups and interviews as a critical area of required services for older people. U3As were selected because opportunities for education were mentioned as integral for older people both in focus groups and in stakeholder interviews. Community centres and libraries were included in the indicator as they not only provide opportunities for education, but also for social interaction. Lastly, public transport stops were included because they were identified as a key factor affecting access to services in focus groups even though questions weren't proposed on the topic.

The three most important and three most used services identified by focus group participants included: shopping, doctors and social club/community centres. These correspond with supermarkets, GPs, community centres, and libraries as measures within the indicator. Places of worship were rated as important but not included in the indicator due to a lack of spatial data. The remaining services in the indicator: hospitals, aged care facilities, public transport stops and Universities of the $3^{\text {rd }}$ Age were included because they were identified as important in either stakeholder interviews or focus groups. Parks were acknowledged as an important 'service' however, weren't able to be included due to lack of state-wide data at an appropriate scale. 
Reduced access to services for older people is clearly identified in a number of LGAs across metropolitan Melbourne (Figure 3). These areas include inner bayside LGAs from the west through to the south east, and some middle suburb LGAs across the western and north-eastern suburbs of Melbourne and growth area LGAs at the outer fringe of north-eastern and south-eastern metropolitan Melbourne. In contrast, the middle and outer eastern, south-eastern, and outer north-west areas of Melbourne are well serviced for older people.

\section{INSERT FIGURE 5 ABOUT HERE}

A very different picture emerges for access to services for older people in regional areas of Victoria (Figure 4). The majority of municipalities in regional Victoria fall into the lower two quintiles of access to services with the exception of the City of Greater Bendigo, which is a major regional centre in northern Victoria, and the City of Mildura in the upper north-west corner of Victoria. The regional municipalities of Mitchell, Murrindindi and Strathboogie are located to the north and north-east of metropolitan Melbourne and fall into the lowest quintile of access to services. These areas already comprise populations with a high proportion of people aged over 60 years in 2011: 16\% in Mitchell (Victorian Government, 2014a); 27\% in Murrindindi (Victorian Government, 2014b); and 33\% in Strathboogie (Victorian Government, 2014c). More importantly, these current population estimations suggest that these proportions will increase to $19 \%$ in in Mitchell, $37 \%$ in Murrindindi and $41 \%$ in Strathboogie by 2031.

\section{Discussion}

The development of a GIS-based indicator of access to services for older people was guided by the views of older people and key stakeholders and provides a useful analysis tool for measuring current access to services across multiple LGAs. The participatory nature of indicator development resulted in a measure that reflects the 
needs of older people themselves, and key policy and practice stakeholders. The key services selected for inclusion in the indicator included hospitals, GPs, Aged Care facilities, public transport stops, supermarkets, community centres, libraries and Universities of the $3^{\text {rd }}$ Age.

Spatial representation of the indicator across Victorian LGAs suggests that many Victorian municipalities require additional services to support the needs of older people, which is particularly important for policy makers and urban planners given Australia's growing older population and spatial variation in ageing patterns (Han \& Corcoran, 2013; Renehan et al., 2012). Older people living in metropolitan Melbourne have better access to services than those in rural areas even though many rural towns have significant older population growth predicted (Department of Planning and Community Development, 2012). These areas require additional medical services, affordable and diverse housing options, affordable transport and community support mechanisms to support the large older populations in these areas. Rural disadvantage was evident in our results and this finding is consistent with a considerable body of literature (Callois \& Aubert, 2007; Davis \& Bartlett, 2008; Giles et al., 2009; Leonard \& Johansson, 2008; McKenzie, 2002; Winterton \& Jeni, 2011). Similarly, poor service provision in Australia's growth area suburbs has also been documented (McDougall \& Maharaj, 2011) and a lack of social services were noted by stakeholders in the growth areas of outer Melbourne.

A key finding from this study is the distinction between what is noted as 'important' versus what are the most highly utilised services. The services included in the new indicator were selected based on the 'importance' and 'utilisation' according to rankings in focus groups and interviews with key stakeholders, and also limitations in spatial data availability. This is a unique contribution of the study and aging in place is enhanced when the services deemed important by older people are recognised through the involvement of older people in the process.

\section{Holistic Approach to Services}

Overall, qualitative results suggest a 'whole is greater than the sum of the parts' approach to service provision. Services do not simply fulfil basic needs but also 
provide important opportunities for social, physical and economic activities. The interrelationships between health, physical and social infrastructure were continually emphasised in stakeholder interviews. Consistent with the WHO Age friendly cities and communities checklist (World Health Organisation, 2007) our study highlights the importance of an integrated approach to providing services in the community. Colocation of services in urban areas is another important consideration in service planning and provision. Co-locating services in areas with good access to public transport and ease of mobility would assist with better integration and connections between services. Co-location would also assist with transport cost barriers (e.g. taxis and community buses) which can be associated with prohibitive expenses and concerns for older people. In comparison, co-location of services might be less favourable for people within rural and regional areas. Stripping services from small local towns to large regional towns might sound cost-effective for policymakers while the reality produces heightened inaccessibility, greater transport limitations and decreased opportunities for social interaction in local regional areas.

\section{Key Services}

Despite the emphasis on a holistic approach to service provision, some key services were mentioned repeatedly both in focus groups and in stakeholder interviews and informed which services were included in the indicator. Supermarkets were included in the indicator as a representation of the shopping experience, which was highlighted as the most important service and most utilised in focus groups. Aged care was included even though it wasn't highlighted in focus groups because for those who require it, aged care services are essential. Hospitals were similarly selected for this reason, and were further emphasised in some stakeholder interviews as important services for older people. GPs were included in the indicator to address health, which was raised in focus groups and interviews as a critical area of required services for older people. U3As were selected because opportunities for education were mentioned as integral for older people both in focus groups and in stakeholder interviews. It is necessary to note that including U3As contradict the idea of integrating services for older people with those for the general population. However, in practice, U3As are much more likely to be utilised by older people than mainstream education centres due the low cost of U3As (Siedle, 2011). Furthermore, many U3A 
programs are supported by mainstream educational institutions (often universities and community centres host U3A classes). Community centres and libraries were included in the indicator as they not only provide opportunities for education, but also for social interaction. They are also important sources for local information, social interaction and support, and ranked highly in focus groups and stakeholders as integral components of the community. Lastly, public transport stops were included in the indicator as results found that transport was a key factor affecting access to services. Transport was included in the indicator to partially address the 'access' in access to services. Transport was noted to be necessary component of access to services in both focus groups and interviews and is confirmed in the literature (Allan, Funk, Reid, \& Cloutier-Fisher, 2011; Broome, Worrall, McKenna, \& Boldy, 2010; Engels \& Liu, 2011; McDougall \& Maharaj, 2011; World Health Organisation, 2007). Indeed, some authors argue that transport is the single most important community element for older people (Engels \& Liu, 2011).

\section{Barriers affecting access to services for older people}

Focus group participants and stakeholders mentioned a range of barriers that affected access to services. These included lack of information and knowledge (including awareness and technical skills), physical barriers (such as lack of physical ability to access services), location of services (too far/hard to get to), affordability (too expensive to use/get to), mental health issues and disabilities (lack physical or mental health to seek out services), safety, transport, housing, ageism and discrimination.

The themes that emerged from qualitative research are consistent with previous research (Davis \& Bartlett, 2008; Everingham, Petriwskyj, Warburton, Cuthill, \& Bartlett, 2009; Levasseur et al., 2011; Manthorpe, Iliffe, Clough, Bright, \& Rapaport, 2009; Municipal Association of Victoria, 2009; World Health Organisation, 2007). For example, lack of information has previously been shown as a barrier, preventing uptake of community services both by older people (World Health Organisation, 2007), and their support networks including family (Stockwell-Smith, Kellett, \& Moyle, 2010:2059). Ageism and discrimination is also well documented (Leonard \& Johansson, 2008; Tahmaseb-McContha, Volkwein-Caplan, \& DiGregorio, 2011) and although anti-discrimination legislation has been introduced in Australia, negative 
attitudes to age remain entrenched in society. This negativity has been internalised by many older people, encouraging feelings of low self-esteem and self-worth (Leonard \& Johansson, 2008; Tahmaseb-McContha et al., 2011). These results are consistent with the WHO Age friendly cities and communities study (World Health Organisation, 2007). Widespread agreement regarding these barriers provides a good basis for future policy development and community discussion.

\section{Service location and population density}

The 'density of services by area' measure suggests that inner metropolitan areas contained the most services per $\mathrm{km}^{2}$, followed by outer metropolitan regions (and larger regional centres). Most regional LGAs lagged behind. A limitation of this measure is that it does not take into account where residents live within an LGA. If residents are living at low densities (which is overwhelmingly the case in regional LGAs), then they will be more sparsely spread across the municipality and will have to travel further to access services. Given that transport and travel time (and associated costs of travel) are listed as a barrier to accessing services, this is an issue for regional LGAs that requires further attention. Future research could look into creating a measure of distance and travel times to services using GIS.

Results also indicate that there are generally fewer older people in regional areas than metropolitan areas although Greater Geelong and Queenscliffe LGAs are notable exceptions with very high proportions of older people in their populations (Figure 4.4). However, for many of the LGAs with low numbers of people over 65 , this demographic formed the largest proportion of the area's population (for instance in Victoria's central west LGAs). This shows that even though there are low numbers of older people in regional LGAs, they form a greater proportion of the population. In metropolitan Melbourne, middle ring LGAs have the highest proportions and numbers of people aged over 65. These findings have important implications for policy makers: municipalities will be affected by the needs of this large cohort of people aged over 65 . 
For example, medical services, affordable transport and community support mechanisms become even more critical with the larger populations of older people in these areas and a growing ageing population in forward Victorian Population projections (Department of Transport Planning and Local Infrastructure, 2014).

It is necessary to note that using an indicator based on services by population to gauge acceptable provision of services can be problematic, particularly for rural areas.

"Because of the low populations, the governments do not regard the servicing of rural communities as cost effective. However, the removal [or lack] of services contributes to the decline of many towns... The decline is particularly stressing for older people who may be moved from their homes and lose informal neighbourhood support" (Leonard \& Johansson, 2008:43)

In rural areas a population threshold size may prevent financial justification for the provision of services while a lack of services based on this could disadvantage communities with small populations. A possible solution to this problem would be the provision of additional services to facilitate 'ageing in place' to maintain existing social connections while reducing the economic and social costs associated with moving to a larger town. The study also emphasised that neighbourhood and street design can affect access to services, with winding streets and cul-de-sacs resulting in poor connectivity and greater distances between residential populations, public transport and services. This suggests that planning at this scale should take into account the need for efficient connectivity within and beyond the neighbourhood, optimising efficient links between residential areas, public transport and services.

\section{Research Limitations}

This research provides a new methodology for measuring access to services for older people but is not without limitations. In terms of the qualitative data collection, participants of the focus groups were self-selected members of an existing peer education group at COTA; they were more attuned to discussing their perspectives, and physically able to travel for meetings. Older people are not a homogenous group and it is likely the sample was not representative of the whole spectrum of abilities 
and interests. The methodology also relied on age categories and was limited by a highest age category of greater than 65 years. Further research might expand the research to specific age groups (e.g. 65-70, 70-75 years) or consider functionality or current levels of independence. Each of these groups will likely have their own issues and priorities. A limitation of the interviews with government stakeholders was the small sample size and future research could involve a wider representation of municipalities across Victoria, particularly to gain a greater understanding or rural and urban issues. Quantitative data collection was limited by data availability and this influenced the services chosen as a basis for the indicator. Extended research could also investigate and incorporate the difficulty involved in getting to services, the quality of services available and specific services for different members of the community.

\section{Conclusions}

In conclusion, this study created an indicator of access to services for older people based on services emphasised as important by older people and key stakeholders from a range of policy and practice perspectives. The indicator provides a comprehensive and easy to understand analysis of services available to older people across multiple geographic regions and is an important tool for future service provision planning. The indicator provides a useful tool to inform the planning of more age friendly communities across Victoria and Australia. 


\section{References}

Allan, D. E., Funk, L. M., Reid, R. C., \& Cloutier-Fisher, D. (2011). Exploring the Influence of Income and Geography on Access to Services for Older Adults in British Columbia: A Multivariate Analysis Using the Canadian Community Health Survey (Cycle 3.1). Canadian Journal on Aging, 30(1), 69-82.

Australian Bureau of Statistics. (2012). Regional Population Growth, cat.no. 3218.0. Australian Bureau of Statistics. (2013). Population Projections Australia. Cat. no. 3222.0.

Australian Institute of Health and Welfare. (2013). The desire to age in place among older Australians. Canberra: AIHW.

Babbie, E. (2011). The Basics of Social Research (5th ed.). Belmont: Wadsworth Cengage Learning.

Broome, K., Worrall, L., McKenna, K., \& Boldy, D. (2010). Priorities for an AgeFriendly Bus System. Canadian Journal on Aging, 29(3), 435-444.

Brown, A. (2011). Plan for Aging in Place Right Here, Right Now. Rehab Management: The Interdisciplinary Journal of Rehabilitation, 24(7), 16-19.

Burton, E. J., Mitchell, L., \& Stride, C. B. (2011). Good places for ageing in place: development of objective built environment measures for investigating links with older people's wellbeing. BMC Public Health, 11, 839-839.

Callois, J.-M., \& Aubert, F. (2007). Towards Indicators of Social Capital for Regional Development Issues: The Case of French Rural Areas. Regional Studies, 41(6), 809821.

Davis, S., \& Bartlett, H. (2008). Review Article: Healthy ageing in rural Australia: Issues and challenges. Australasian Journal on Ageing, 27(2), 56-60.

Davis, S., Crothers, N., Grant, J., Young, S., \& Smith, K. (2012). Being involved in the country: Productive ageing in different types of rural communities. Journal of Rural Studies, 28(4), 338-346.

Department of Planning and Community Development. (2012). Victoria in Future 2012: Population and Household Projections 2011-2031 for Victoria and its Regions. In S. G. o. Victoria (Ed.). Melbourne: Spatial Analysis and Research, Department of Planning and Community Development.

Department of Transport Planning and Local Infrastructure. (2014). Victoria In Future: Populations and Household Projections to 2051. Melbourne.

Engels, B., \& Liu, G.-J. (2011). Social exclusion, location and transport disadvantage amongst non-driving seniors in a Melbourne municipality, Australia. Journal of Transport Geography, 19(4), 984-996.

Engels, B., \& Liu, G.-J. (2012). Ageing in Place: The Out-of-Home Travel Patterns of Seniors in Victoria and its Policy Implications. Urban Policy and Research, 31(2), 168-189.

Everingham, J.-A., Petriwskyj, A., Warburton, J., Cuthill, M., \& Bartlett, H. (2009). Information Provision for an Age-Friendly Community. Ageing International, 34(1/2), 79-98.

Gardner, P. J. (2011). Natural neighborhood networks: Important social networks in the lives of older adults aging in place. Journal of Aging Studies, 25(3), 263-271.

Giles, L. C., Halbert, J. A., Gray, L. C., Cameron, I. D., \& Crotty, M. (2009). The distribution of health services for older people in Australia: where does transition care fit? Australian Health Review, 33(4), 572-582. 
Han, J. H., \& Corcoran, J. (2013). Ageing Australia: changing location patterns of older people in South East Queensland. Australian Planner, 51(1), 2-14.

Leonard, R., \& Johansson, S. (2008). Policy and practices relating to the active engagement of older people in the community: a comparison of Sweden and Australia. International Journal of Social Welfare, 17(1), 37-45.

Levasseur, M., Gauvin, L., Richard, L., Kestens, Y., Daniel, M., \& Payette, H. (2011). Associations between perceived proximity to neighbourhood resources, disabilitym and social participation amonth community-dwelling older adults: Results from the VoisnyNuAge Study. Archives of Physical Medicing and Rehabilitation, 92, 19791986.

Lipmann, B. (2009). Elderly Homeless Men and Women: Aged Care's Forgotten People. Australian Social Work, 62(2), 272-286.

Lui, C.-W., Everingham, J.-A., Warburton, J., Cuthill, M., \& Bartlett, H. (2009). What makes a community age-friendly: A review of international literature. Australasian Journal on Ageing, 28(3), 116-121.

Manthorpe, J., Iliffe, S., Clough, R., Bright, L., \& Rapaport, J. (2009). 'We are not blaming anyone, but if we don't know about amenities, we cannot seek them out': Black and minority older people's views on the quality of local health and personal social services in Englad. Ageing and Society, 29, 93-113.

McDougall, A., \& Maharaj, V. (2011). Closing gaps on the urban fringe of Australian capital cities: an investment worth making. Australian Planner, 48(3), 131-140.

McKenzie, F. (2002). A shocking impact. Australian Planner, 39(4), 194-201.

Municipal Association of Victoria. (2009). Submission to the Inquiry into Opportunities for Participation of Victorian Seniors. Melbourne: Municipal Association of Victoria.

Olsberg, D., \& Winters, M. (2005). Ageing in place: intergenerational and intrafamilial housing transfers and shifts in later life.

Plouffe, L. A., \& Kalache, A. (2011). Making communities age friendly: State and municipal initiatives in Canada and other countries. Gaceta Sanitaria, 25(S), 131-137. Renehan, E., Dow, B., Lin, X., Blackberry, I., Haapala, I., Gaffy, E., et al. (2012). Healthy ageing literature review. Melbourne, Victoria: Department of Health.

Siedle, R. (2011). Principles and practices of mature-age education at U3As. Journal of Adult Learning, 51(3).

Stockwell-Smith, G., Kellett, U., \& Moyle, W. (2010). Why carers of frail older people are not using available respite services: an Australian study. Journal of Clinical Nursing, 19(13/14), 2057-2064.

Tahmaseb-McContha, J., Volkwein-Caplan, K., \& DiGregorio, N. (2011). Culture, Aging and Well-being: The Importance of Place and Space. International Journal of Sport \& Society, 2(2), 41-48.

Victorian Government. (2014a). Mitchell (S) One Page Profile. Melbourne: Department of Transport, Planning and Local Infrastructure.

Victorian Government. (2014b). Murrindindi (S) One Page Profile. Melbourne: Department of Transport, Planning and Local Infrastructure.

Victorian Government. (2014c). Strathboogie (S) One Page Profile. Melbourne: Department of Transport, Planning and Local Infrastructure.

Wiles, J., Leibling, A., Guberman, N., Reeve, J., \& Allen, R. (2011). The Meaning of 'Ageing in Place' to Older People. The Gerontologist, 52(3), 357-366.

Wilkinson-Meyers, L., Brown, P., McLean, C., \& Kerse, N. (2014). Met and unmet need for personal assistance among community-dwelling New Zealanders 75 years and over. Health and Social Care in the Community, 22(3), 317-327. 
Wimmer, R. D., \& Dominick, J. R. (2010). Mass Media Research: An Introduction (9th edition ed.). Boston: Wadsworth CENGAGE Learning.

Winterton, R., \& Jeni, W. (2011). Does place matter? Reviewing the experience of disadvantage for older people in rural Australia. Rural Society, 20(2), 187-197.

World Health Organisation. (2007). Global Age-friendly Cities: A Guide. Geneva: World Health Organisation. 
Table 1: Focus Group Questions Presented to Older People and Key Stakeholders

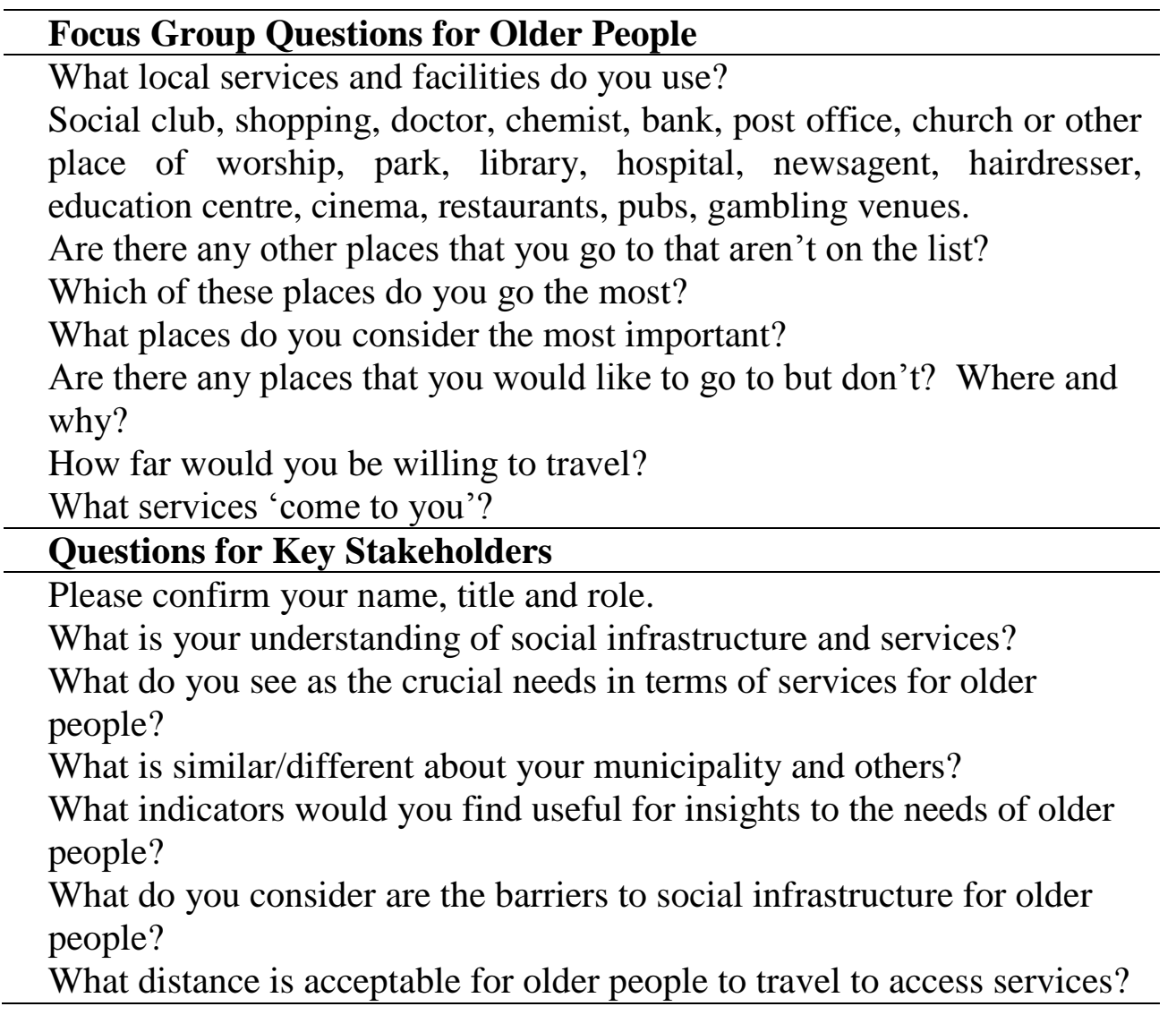




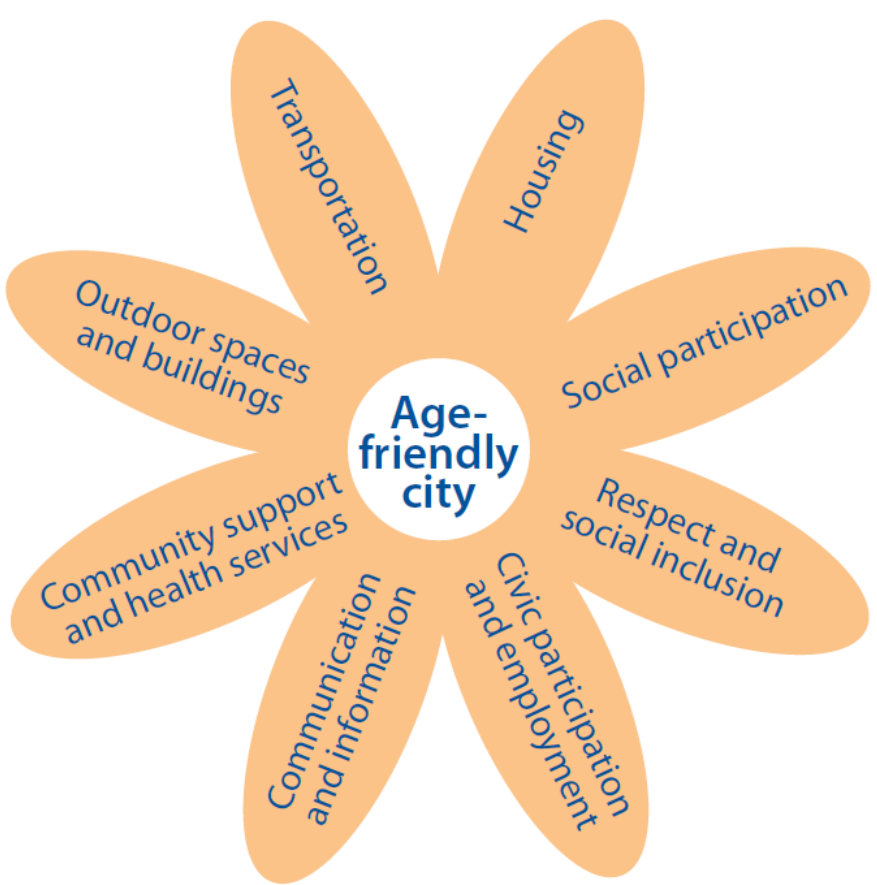

Figure 1: Age Friendly City topic areas (World Health Organisation, 2007). 
Determine key services for

older people

Conceptually develop an

indicator of access

Obtain and geocode data

Calculate the indicator

Map the indicator

Figure 2: Overview of Methodology 


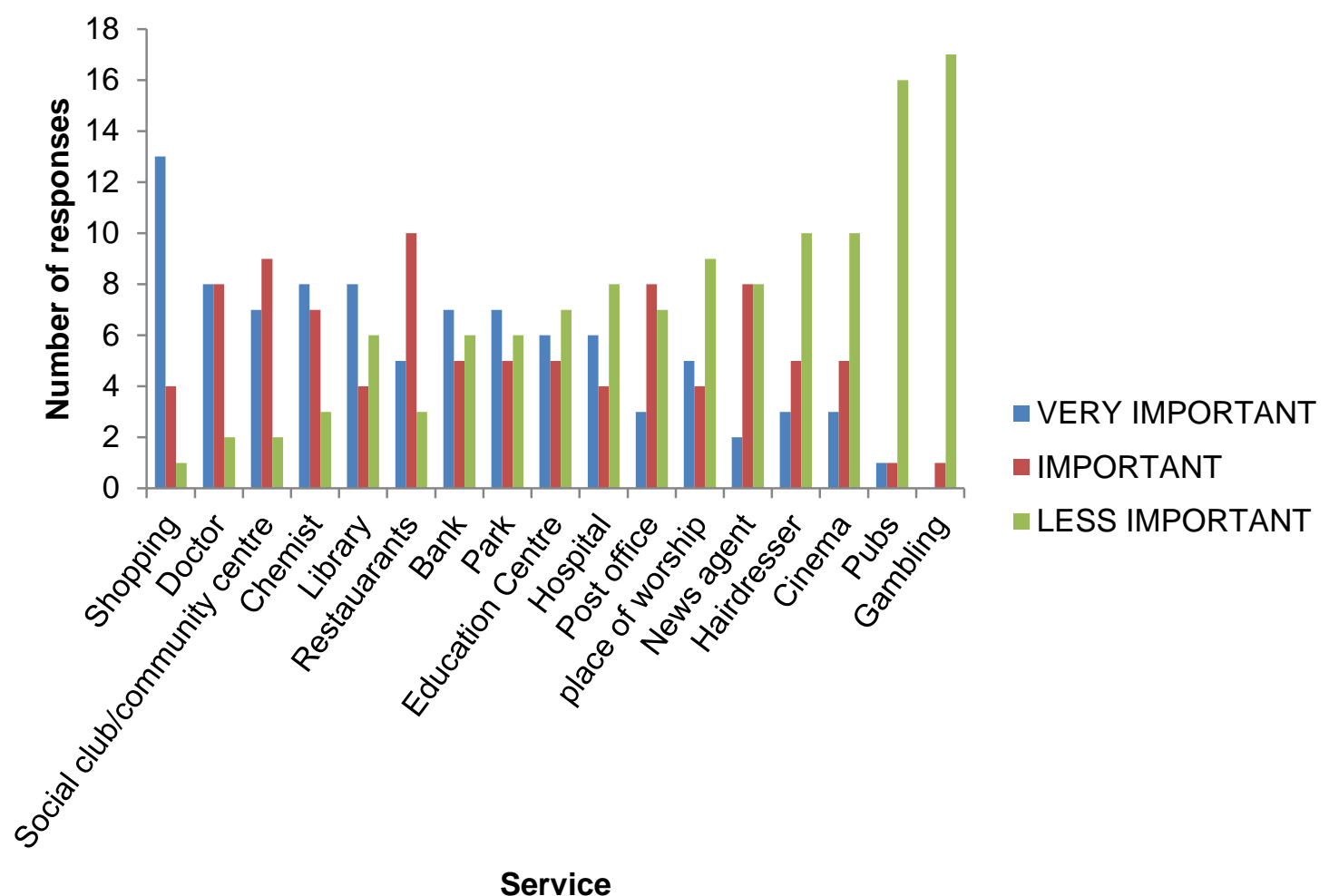

Figure 3: Services Ranked According to Importance Ratings 


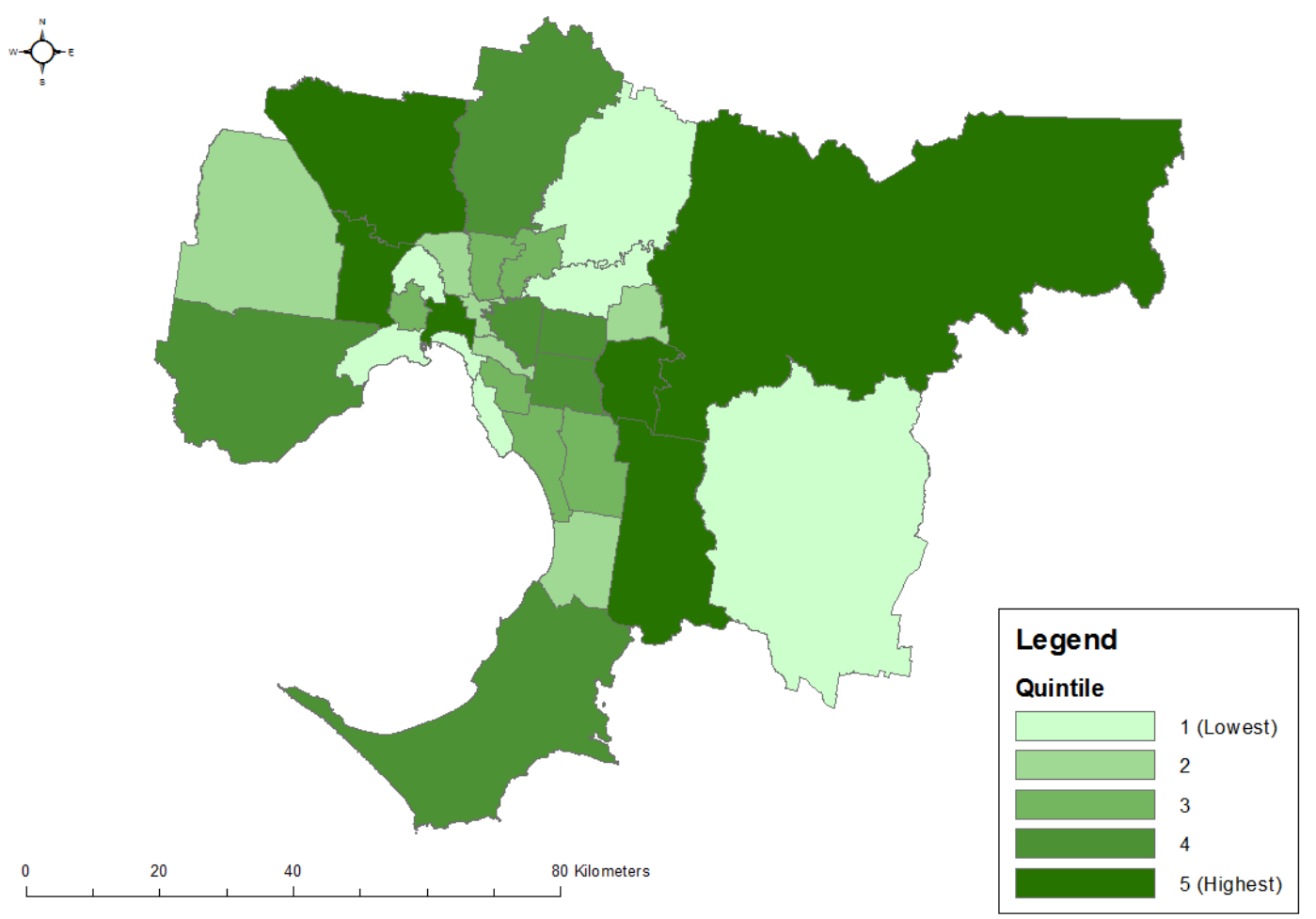

Figure 4: Access to Services for Older People in Metropolitan Melbourne Local Government Areas 


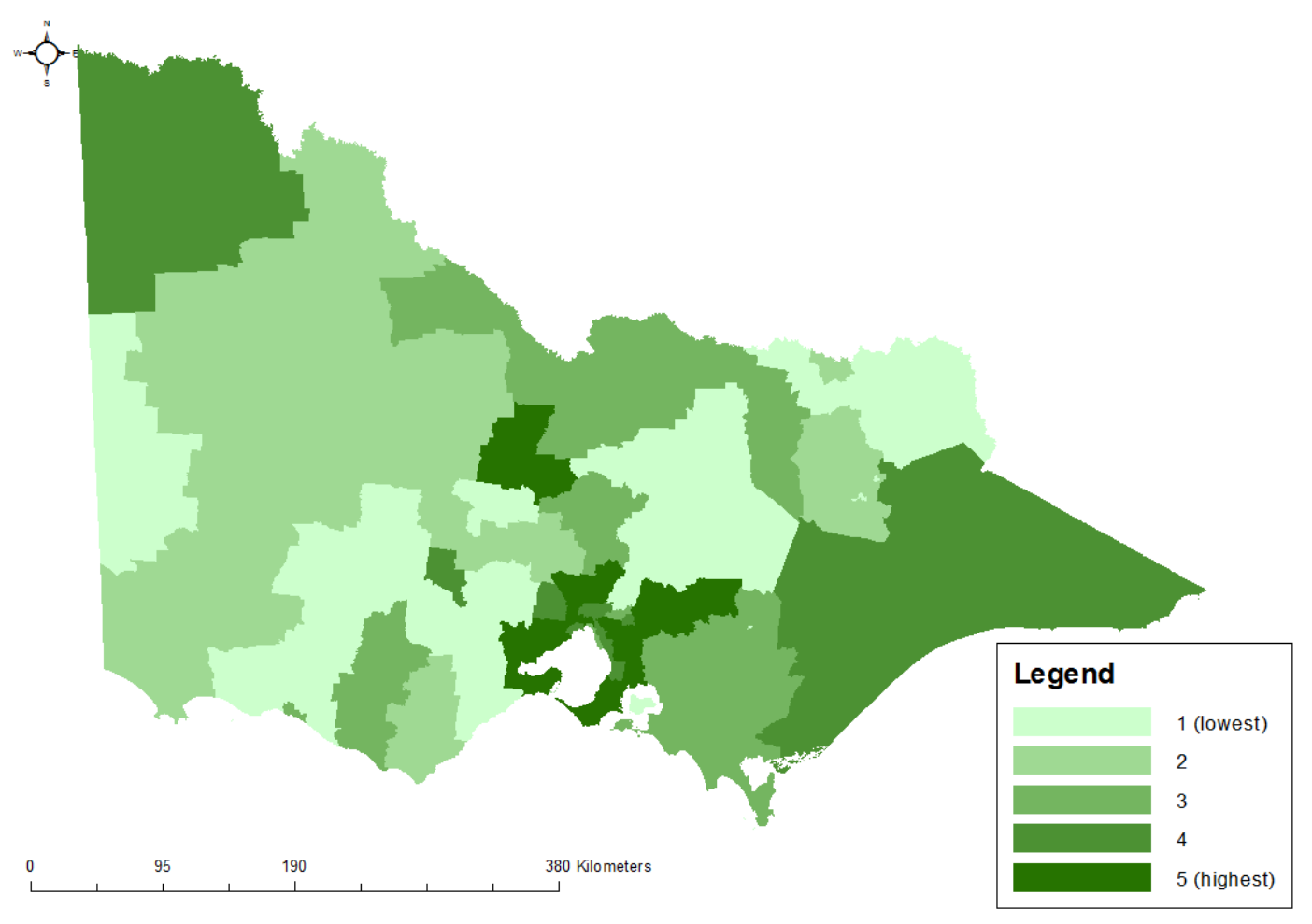

Figure 5: Access to Services for Older People in Rural Victorian LGAs 


\section{University Library}

\section{- M M N E R VA A gateway to Melbourne's research publications}

Minerva Access is the Institutional Repository of The University of Melbourne

Author/s:

Lowen, T;Davern, MT;Mavoa, S;Brasher, K

Title:

Age-friendly cities and communities: access to services for older people

Date:

2015-10-02

Citation:

Lowen, T., Davern, M. T., Mavoa, S. \& Brasher, K. (2015). Age-friendly cities and communities: access to services for older people. AUSTRALIAN PLANNER, 52 (4), pp.255-265. https://doi.org/10.1080/07293682.2015.1047874.

Persistent Link:

http://hdl.handle.net/11343/57101 